\title{
Uiestinnän udikutus
} ajan kïssittämiseen

\begin{abstract}
Vaikka viestintä ja aika liittyvät useilla eri tavoilla yhteen, näiden yhteyksien tutkiminen on jäänyt yhteiskuntatieteissä lähes huomiotta. Viestinnän tutkimuksista tai teorioista - varsinkaan vanhoista klassikoista - löytyy harvoin viittauksia aikaan. Marjorie Fergusonin sanoin (1990, 163-164): “Tämä puuttuva kategoria vaatii, että kaikkien Lasswellin työn uudelleen arviointien täytyy alkaa siitä mitä kutsun hänen 'poisjättämisen synnikseen.' Minua on jo pitkään kummastuttanut, että se pyhä teksti johon useimmiten vedotaan - Lasswellin lause viestintäprosessista - on sokea sanoman temporaalisille, historiallisille ja kontekstuaalisille puolille. Lauseesta 'kuka sanoo mitä kenelle mitä kanavaa käyttäen ja millä vaikutuksella' puuttuu milloin, aivan samoin kuin siitä puuttuu missä“.
\end{abstract}

Aika ei ole jäänyt vähälle huomiolle

Artikkelissa kartoitetaan sitä, kuinka viestințä on vaikuttanut aikaan ja sen kokemiseen. Ongelmaa on tarkasteltu seuraamalla ajan käsittämiser mLitoksia viestintätapojen muuttuessa. Artikkelissa esitetään, että viestinnän muutokset ovat vaikuttaneet viiteen ajan aspektiin: aikakäsityksen pääpiirteisiin, aikaperspektiiviin, arjen temporaalisuuteen, elämänrytmın nopeutumiseen ja ajan merkityksen kasvuun. vain viestinnän tutkimuksessa, vaan yhteiskuntatieteissä laajemminkin. Koska suuri osa viestintää ja aikaa käsittelevistä teorioista löytyy sosiologian kirjoista, on ajan "poisjättämisen synti" yhteiskuntatieteissä vaikuttanut suoraan myös viestintää ja aikaa koskevan materiaalin vähyyteen. Ne sosiologit, jotka ovat käsitelleet aikaa, korostavat lähes kuorossa ajan tärkeyttä ja valittavat tutkimuksen vähyyttä. Yksi aikaa laajasti käsitelleistä sosiologeista on Eviatar Zerubavel, joka on todennut muun muassa (1981, ix):

Vaikka aika on epäilemättä yksi sosiaalisen maailman keskeisimpiä ulottuvuuksia, sosiologit ovat tähän asti laiminlyöneet sen tutkimista suhteellisen paljon. Sosiologit, jotka ovat käsitelleet aikaa - jos lainkaan - ovat pitäneet sitä vain muiden ilmiöiden, kuten sosiaalisen muutoksen tai vapaa-ajan osana ja tuskin koskaan omana oikeutettuna aiheenaan... [Tämä ehkä siksi että] aika on yhteiskunnassa aina läsnäoleva osatekijä ja sellaisena helposti itsestäänselvyys, jota ei oteta erityisen huomion kohteeksi... [K]uitenkin juuri siksi, että aika on niin oleellinen parametri sosiaalisessa maailmassa, sitä ei voi enää ohittaa.

Ennen kuin siirryn perustelemaan yksityiskohtaisemmin väitettä viestinnän ja ajan liittymisestä yhteen, haluan vielä havainnollistaa sitä, kuinka vähälle huomiolle viestintä on jäänyt puhuttaessa niistä tekijöistä, jotka ovat vaikuttaneet ihmisen nykyiseen käsitykseen ajasta. Laajassa aikaa käsittelevässä teoksessaan sosiologi Jorma Pohjanen (1992, 134-135) toteaa: “Modernia aikakäsitystä ei voida selittää vain yhdellä tai kahdella tekijällä, kuten edellinen tarkastelu on osoittanut, vaan kyse on monien tekijöiden yhteisvaikutuksesta ja yhteensattumisesta, joiden ansiosta uusi aikakäsitys on syntynyt". Tämän jälkeen Pohjanen luettelee toistakymmentä eri tekijää, jotka ovat vaikuttaneet aikakäsitykseen, esimerkiksi 
luostarit, kellon, teollisuuden, kaupungistumisen ja liikenteen, mutta ei mitään viestintätapoihin tai -välineisiin liittyvää. Tämän artikkelin tarkoituksena on valottaa Pohjasen esittämää ilmiötä juuri viestinnän näkökulmasta eli osoittaa viestinnän merkitys aikakäsityksen ja yhteiskunnan temporaalisten rytmien muuttajana.

Lähestymistavaltaan artikkeli lukeutuu Michael Schudsonin $(1991,177)$ luokituksen mukaan viestinnän makrohistoriaan kuuluvaksi suuntaukseksi. Tämä tutkimussuunta pyrkii löytämään vastauksia siihen, kuinka viestinnän historian avulla voidaan selittää ihmisen toimintaa. Se poikkeaa muista viestinnän historian tutkimussuunnista siinä, että se painottaa viestinnän merkitystä yhteiskunnan muutosten lähteenä eikä päinvastoin, kuten muut lähestymistavat.

Keskustelun viestinnän ja ajan yhteen liittymisestä käynnisti kanadalainen tutkija Harold Adams Innis 1950-luvulla kolmella perättäisellä kirjallaan (1950; 1951; 1952), joissa hän käsitteli viestinnän ja ajan yhteyttä pitkälti vallankäytön näkökulmasta. Innis tarkasteli sitä, miten tietynlaiset viestintävälineet toimivat suhteessa aikaan ja tilaan ja miten tämä vuorostaan vaikuttaa yhteisöjen hallitsemiseen.

Ajatus viestinnän ja ajan yhteyksistä on löydettävissä jo Emile Durkheimin (1980, 391-393) teoriasta mielen kategorioista, jotka ovat sosiaalisia ilmiöitä ja näin yhteisön hiomia. Tällainen ilmiö on esimerkiksi ajan kategoria. Kategoriat eivät välttämättä ole olemassa a priori tullakseen ilmoille yhteisöstä, vaan niiden ilmentämillä asioilla on sosiaalinen luonne, joka myös on yhteisön luoma. Yhteisön luoman ajan kategorian perustana on siis yhteisön luoman sosiaalisen elämän rytmi. Durkheim ei yksilöi tarkemmin tekijöitä, jotka vaikuttavat kategorioiden syntyyn, mutta niiden lähde on jo itse kysymyksessä: "Miten [kategoriat] sitten ovat ottaneet yhteiskunnasta mallit, joiden mukaisesti ne rakentuvat?" Aikakäsityksen rakennustekijöinä ovat siis mallit, joita löytyy yhteiskunnasta.

Mitkä tekijät sitten vaikuttavat käsitysten ja kategorioiden syntyyn? Jack Goodyn mukaan (1968, 36; 1977, 10, 36-37, 150-151) yksi tärkeimmistä kulttuurin välittäjistä historian aikana on ollut viestintä. Juuri viestinnän avulla ihminen siirtää kulttuuriaan ja opittua käyttäytymistään sukupolvelta toiselle, myös aikaan liittyvää käyttäytymistään.

Sosiaalinen elämä olisi tuskin mahdollista ilman ihmisen kykyä suhtautua aikaan standardina. Huomaamme tämän esimerkiksi epämiellyttävästä tunteesta, joka seuraa, jos kellomme on pysähtynyt tai emme muista mikä päivä on meneillään. Olemme jääneet hetkeksi intersubjektiivisen sosiaalisen maailman ulkopuolelle (Julkunen 1989, 18). Tarvitsemme ajallista standardisointia lähes kaikilla sosiaalisen elämämme alueilla, esimerkiksi jo pelkkä tapaamisten sopiminen vaatii yhteistä käsitystä ajasta.

Durkheimin mukaan (1980, 391-394) yksilö elää ajassa, hänellä on tietty 
suuntautumistapa aikaan nähden, henkilökohtainen kokemus siitä, kuinka aika kuluu sekä yksilöllinen elämänrytmi. Kaiken ympärillä on kuitenkin kollektiivisen elämän rytmi, sosiaalinen aika. Ihmisten yhteistoiminta on mahdollista vain, jos he ovat päässeet yhteisymmärrykseen ajasta ja jokainen tajuaa ajan samalla tavalla. Yksilöllä ei sinänsä ole tarvetta ajan käsitteelliseen mieltämiseen, kuten ei eläimilläkään, jotka toimivat aistimustensa pohjalta. Yhteiskunta edellyttää kuitenkin sosiaalista aikaa eli koko ryhmää koskevaa yhteistä käsitystä elämän rytmistä: aikaa, jota yksilö ei voi oppia kuin juuri yhteiskunnan välityksellä.

Modernissa länsimaisessa yhteiskunnassa juuri viestimet ovat niitä tekijöitä, joiden kautta yhteisöjen aikatietoisuus, arjen temporaalisuus ja aikakäsitys syntyvät. Historiallinen tarkastelu viestinnän suullista, käsinkirjoitettua, painettua ja sähköistä kautta koskien osoittaa, kuinka viestinnän muutokset ovat vaikuttaneet ajan viiteen eri aspektiin: aikakäsityksen pääpiirteisiin, aikaperspektiiviin, arjen temporaalisuuteen, elämänrytmin nopeutumiseen ja ajan merkityksen kasvuun.

\section{Aikakäsitys pirstoutui}

Viestintätapojen muutokset ovat vaikuttaneet merkittävästi aikakäsityksen kolmen pääpiirteen muuttumiseen: suullisen viestinnän kauden luonnonmukainen, konkreettinen ja epäjatkuva aikakäsitys on muuttunut sähköisen kauden keinotekoiseksi, abstraktiksi ja pirstoutuneen lineaariseksi käsitykseksi. Luonnonmukaisen aikakäsityksen yhteisöissä elettiin luonnon kiertokulun mukaan, ja mikäli ajan laskemista tarvittiin, se perustui luonnon ja vuodenaikojen rytmeihin (EvansPritchard 1974, 94-96). Muutos kohti keinotekoisempaa ajankäytön jaottelua tapahtui kirjoitustaidon mukanaan tuomien kalentereiden ja aikataulujen myötä, ja painotaidon keksiminen mahdollisti niiden vaikutusten leviämisen laajalle yhteiskuntaan. Luontoon liittyvä aikakäsitys mureni entisestään, kun lennättimet alkoivat säädellä junien kulkemista ja lähettää aikasignaaleja ensin kaupungista ja sitten maasta toiseen. Rautateiden, lennättimen ja kansainvälistyvän viestinnän vaatimukset saivat aikaan kansainvälisen standardiajan ja aikavyöhykkeiden asettamisen maailmaan: ajasta tuli samalla selkeästi ihmisen eikä luonnon määrittämä käsite.

Viestimillä on edelleen suuri merkitys standardiajan välittämisessä yhteisöihin, sillä "oikean" ajan voi aina tarkistaa niin puhelimesta, radiosta kuin televisiostakin. Kirjalla, elokuvalla, radiolla ja televisiolla on kyky yleisen ajan välittämisen ohella myös muokata aikaa omiin tarpeisiinsa muuttamalla sen luonnollista kulkua. Ihmiset ovat jo tottuneet siihen, että kirjoissa ja elokuvissa aikaa voidaan tiivistää ja venyttää sekä siihen, että radio ja televisio "leikkaavat" aikaa ja tapahtumia pois lähetyksistään, mikä irrottaa tapahtumien kulun niiden alkuperäisestä ajoituksesta (Tuchman 1980, 109-110). Ihmisen luoman ajan huipentuma on tietokoneiden nanosekuntikulttuuri, jonka aikayksiköt ovat niin pieniä, ettei ihminen kykene aisteillaan havaitsemaan tai kokemaan niiden kulumista (Bolter 1984, 100-101).

Oraalisen kulttuurin aikakäsityksen toinen pääpiirre, sen konkreettisuus, oli seurausta koko ajattelutavan liittymisestä konkreettisiin käsitteisiin. Mitään abstrakteja ajan kulumisen tai edes ajan itsensä määritelmiä ei ollut, joten tapahtumat ajoitettiin vertaamalla kahden tapahtuman ajallista suhdetta toisiinsa (Hallowell 1937, 669). Esimerkiksi "riisin keittäminen" saattoi tarkoittaa puolta tuntia ja "heinäsirkan paistaminen" hetkeä (Sorokin \& Merton 1990, 59).

Tilanne muuttui kahdella tapaa kirjoitustaidon myötä. Ensinnäkin kirjoitustaito vaikutti abstraktin ajattelun syntyyn, mikä teki tietä ajan kategorian kehittymiseile ihmisen ajatuksissa ja puheessa (Goody 1977, 37, 44). Kirjoittaminen loi 
uudenlaisen suhteen sanan ja sen referentin välille: kirjoitettu sana on abstraktimpi kuin lausuttu. Se ei ole samalla tavalla kiinni ajassa, paikassa ja henkilössä kuin puhuttu sana, millä on merkittävä vaikutus ajattelun kannalta (Goody \& Watt 1962, 321). Kirjoittaminen oli kielen synnyn jälkeen tärkein viestinnän muutos. Se muutti itse kieltä sitoessaan puhutun sanan pysyvään muotoon. Kirjoittaminen ei vain säilyttänyt puhetta ajassa, se myös muutti puhetta tuomalla siihen abstrakteja osia. Sanojen muuttumisella "häviävistä kuuloon perustuvista signaaleista kestäviksi objekteiksi" oli merkittäviä vaikutuksia ihmisten tapaan viestiä: koska viestit olivat saaneet pysyvän muodon, oli viestintä mahdollista yli aika- ja paikkarajojen. Kirjoittaminen ei syntynyt vain suullisen viestinnän avuksi, vaan se saattoi säilyttää myös jo "kuollutta" puhetta, kuten esimerkiksi latinan kielen. (Goody 1977, 10-15, 76-78)

Kirjoittaminen mahdollisti varhaisempien, tuntemattomien kirjoittajien tekstien kritisoimisen. Aiemmin kaikki viestintä tapahtui "kasvoista kasvoihin", mutta kirjoittamisen yleistyessä oli mahdollista verrata samanaikaisesti vanhoja ja uusia tietolähteitä. Kun lausuma sai kirjallisen muodon, sitä voitiin tutkia paljon yksityiskohtaisemmin kuin puhutussa muodossa. Kirjoitettu puhe ei ole enää tilanteessa kiinni, se on "ajatonta", mutta myös abstraktimpaa kuin puhe, koska se on irrallaan alkuperäisestä lähteestään. (Goody 1977, 37, 44)

Toiseksi kirjoitustaidon tuomat kalenterit antoivat mahdollisuuden ajoittaa tapahtumia abstraktien määreiden, kuten päivien, viikkojen tai vuosien mukaan konkreettisten tapahtumien sijasta. Päivämäärät ja ikävuodet otettiin vähitellen käyttöön koko yhteiskunnan toiminnassa.

Painotaito vahvisti jälleen näitä kirjoitustaidon tuomia muutoksia moninkertaistamalla niiden vaikutukset: kirjojen avulla abstrakti ajattelu alkoi levitä kaikkiin yhteiskunnan ryhmiin, mikä vähensi vanhan konkreettisen ajattelutavan yleisyyttä entisestään. Ajan konkreettisiin tapahtumiin liittyvä määrittäminen ei kuitenkaan koskaan hävinnyt kokonaan. Vaikka sitä käytetään harvoin virallisissa yhteyksissä, se kuuluu kiinteästi ihmisten puheeseen: "lapseni syntymän aikoihin", "armeija-aikana" tai "iltauutisten jälkeen" ovat määreitä, joissa abstrakti aika on korvattu konkreettisella ilmauksella. Konkreettinen ajanmääritystapa on esimerkki suullisen viestinnän ajan ominaisuudesta, joka on säilynyt läpi kaikkien viestinnän vaiheiden nykypäivään asti.

Aikakäsityksen kolmas pääpiirre, kysymys ajan jatkuvuudesta, on myös muuttunut viestintätapojen muuttuessa. Oraalisella kaudella aika ei ollut välttämättä jatkumo. Esimerkiksi Algerian kabyliviljelijöille aika on ollut sarja heterogeenisia ajan "saarekkeita" (Bourdieu 1990, 221-224). Oraalisen kauden epäjatkuva aikakäsitys alkoi muuttua kirjoitustaidon tuoman asioiden lineaarisen ja kronologisen järjestämisen myötä, kun muun muassa myyttien irrallisia ja syklisiä tarinoita alettiin järjestää kronologisiksi kokonaisuuksiksi (Broms 1984, 41, 187). Kirjojen selkeän kronologinen muoto vahvisti lineaarisuuden ajatusta aikakäsityksessä. Painotaidon käynnistämä kirjojen nopea tuotanto levitti uusia ajatuksia tehokkaasti yhteiskunnassa eteenpäin, ja ajasta tuli yhä selkeämmin jatkumo ihmisten ajattelussa.

Sähköisen viestinnän aika on kuitenkin vaikuttanut myös ajan jatkumon pilkkoutumiseen pienempiin osiin: jo lennätin sai aikaan uutiskielen pätkimisen mahdollisimman lyhyisiin ja niukkoihin palasiin. Lennättimen nopeus ei muuttanut vain lehtien sisältöä vaan myös koko uutiskielen: koska jokainen sähköisesti lähetetty sana maksoi, täytyi toimittajien tiivistää sanottavansa lyhyimpään mahdolliseen muotoon. Toimittajat alkoivat myös välttää monimerkityksisiä sanoja, mikä pudotti osan sanoista käytöstä ja teki toisista yleisempiä. Adverbiaalilauseet virkkeiden alussa olivat erityisen "vaarallisia", sillä ne sotkeentuivat helposti edelliseen virkkeeseen, koska välimerkkejä käytettiin erittäin vähän lennätintekstissä (Kern 1983, 115). Sähkekieli muutti sanomalehtien vanhan kirjamuotoisen 
kirjoitustyylin huomattavasti mosaiikkimaisemmaksi kokoelmaksi maailman tapahtumia (McLuhan 1984, 234, 240).

Radio ja televisio ovat jatkaneet samaa asioiden pilkkomista sekä katkonaisen ohjeimarakenteensa että uutisten pätkittäisyyden kautta. Toisiaan seuraavilla ohjelmilla tai uutisilla ei ole mitään kronologista järjestystä keskenään, ja mainokset pilkkovat niitä entistä pienempiin osasiin (Carpenter 1960, 164-165). Tällä on ollut vaikutusta ihmisten tapaan seurata ohjelmia: pitkät ja hitaat ohjelmat eivät välttämättä kykene pitämään ihmisten mielenkiintoa yllä aikana, jolloin korostetaan tapahtumien nopeata ja vaihtuvaa tempoa ja jolloin ihmiset voivat seurata jopa kahta ohjelmaa yhtä aikaa eri kanavilta (Zerubavel 1981, 58).

\section{Aikaperspektiivistä kolmiulotteinen}

Näiden aikakäsityksen kolmen piirteen ohella toinen suuri ajan aspekti, johon viestintä on vaikuttanut merkittävästi, on aikaperspektiivin muodostuminen. !hminen pystyy nykyisin kurottamaan huomattavasti pidemmälle niin menneisyyteen kuin tulevaisuuteenkin kuin aiemmin. Oraalisen kulttuurin kaudella aikaa ei edes ajateltu kolmiulotteisena jatkumona, vaan inmiset elivät nykyhetkessä ja viittasivat korkeintaan aivan lähimenneisyyteen ja -tulevaisuuteen (Carpenter $1960,162,167)$. Aikaperspektiivissä tapahtui suurin muutos kirjoitustaidon tullessa: historiankirjoituksen avulla menneisyys alkoi erottua omaksi itsenäiseksi kokonaisuudekseen ja aikataulut avasivat tulevaisuuden uutena suunnittelun alueena (Goody 1968, 38-41). Nykyhetki alkoi samalla näyttää pisteeltä menneisyyden ja tulevaisuuden välissä.

Kirjoittamisen myötä ihmisen menneisyydestä alkoi tulla objektiivista todellisuutta, myytti ja historia erosivat toisistaan. Myytin ja historian ero tapahtui, kun inminen alkoi aakkosten keksimisen jälkeen kirjoittaa muistiin menneisyyttään ja verrata eri tekstejä toisiinsa. Termi "esihistoriallinen" kuvaa hyvin juuri "esikirjallisia" kansoja, sillä kuten esimerkiksi Goody on kirjoittanut (1968, 39): "tiukasti tulkittuna historia alkaa kirjoittamisen myötä". Oraalisista kulttuureista puuttui käsitys nykyhetkestä tiettynä pisteenä, mikä on tunnusomainen piirre juuri kirjallisille kulttuureille. Kirja on ihanteellinen väline evoluution ja kehityksen kuvaamiseen, koska kirja itsessään on muodoltaan lineaarinen: sen tapahtumilla on järjestys ja suunta tietyllä aikajanalla.

Kirjoitustaito antoi mahdollisuuden myös aikataulujen käyttöönottoon. Ajan jakaminen eri toimintoihin ei ollut enää vain muistista kiinni, kun toimintojen kirjoittaminen muistiin oli mahdollista. Aikataulujen ja suunnitelmien avulla ihminen sai päivään mahtumaan myös useampia toimintoja, ja näin kirjoitustaito ei vaikuttanut vain menneisyyden käsittämiseen vaan myös nykyisyyden ja tulevaisuuden suunnitteluun. Tulevaisuuteen kirjoittaminen vaikutti ennen kaikkea parantamalla edellytyksiä pitkän tähtäyksen suunnitelmien ja aikataulujen tekemiseen. (Goody 1968, 38-41)

Kirjoitustaidon keksimisen vaikutuksia aikaperspektiiviin on summannut Anthony Giddens (1984, 301), joka toteaa:

[K]irjoittamisen kehittyminen on "lineaarisen aikatietoisuuden" synnyn perustana. Tämä aikatietoisuus tuli sitten läntisessä maailmassa historisiteetin .. perustaksi. Kirjoittaminen antaa mahdoilisuuden ... yhteyteen "kaukaisten sukupolvien" kanssa, mutta lisäksi ehkä juuri sen materiaalisen ilmenemismuodon lineaarisuus rohkaisee tietoisuutta tulkitsemaan ajan kulumista sarjamaisena prosessina, joka johtaa asteittaisena etenemisenä "yhdestä" pisteestä "poispäin toiseen" pisteeseen. On luultavasti perusteltua väittää, ettei "aikaa" - eikä perinnettäkään eroteta perinteisissä kulttuureissa erilliseksi "ulottuvuudeksi", ei ainakaan aikatietoisuuden merkityksessä. 
Kirjojen yleistyminen vahvisti tätä uutta tietoisuutta omasta paikasta historian tapahtumien ketjussa, ja ihmisistä - etenkin keskiluokasta - tuli entistä aikatietoisempia lukutaidon levitessä (Riesman 1960, 113). Kirjojen avulla aikaperspektiivi sai myös uusia muotoja, kun tekstit kykenivät viemään lukijansa pitkälle sekä menneisyyteen että tulevaisuuteen myös fantasian keinoin. Tämä "aikamatkailu" lisääntyi entisestään elokuvan myötä: mikään tulevaisuus ei ollut liian kaukana kuvattavaksi elokuvan maailmassa. Elokuva toi myös uuden tavan kuvata historian kulkua elävässä muodossa, mikä hätkähdytti varhaisia elokuvissakävijöitä, jotka pitivät filmille tallennettua henkilöä kuolemattomana (Mumford 1963, 242245, 338-340). Kuolemattomuuden tavoittelu oli nostanut päätään jo ennen elokuvaa, kun kirjojen kirjoittajille oli valjennut heidän tekstiensä mahdollinen säilyminen jälkimaailmalle (Smith 1980, 5-7).

Myös muut viestimet alkoivat tallentaa historiaa uudessa muodossa: sanomalehden, radion ja television tapa kerätä päivän historiaa on melko samanlainen. Jokainen näistä viestimistä kerää päivän verran maailman tapahtumia kokoelmaksi, joka vanhenee yleensä jo seuraavana päivänä. Uutiset elävät 24 tunnin elämää jatkuvana virtana, mikä on tehnyt ihmisille vaikeaksi asioiden kokonaisuuksien hahmottamisen ja syiden ja seurauksien löytämisen. Yhteys menneisyyteen on siten heikentynyt, millä on vaikutusta myös yhteiskunnan päätöksentekoon. Menneisyyden tietoja ei välttämättä osata enää käyttää hyväksi suunniteltaessa tulevaisuutta, kun tietoa tulvii jo nykyhetkessä niin paljon, ettei sen perusteellinen käsittely ole mahdollista. Tämä vaikeuttaa asioiden pitkäjänteistä suunnittelua. Tietokoneet ovat mahdollistaneet erilaisten visioiden ja todennäköisyyksien nopean laskemisen ja menneisyyden tiedon järjestämisen yhä uudeileen ja uudelleen uusiksi tietolähteiksi (Rifkin 1987, 98-100, 155, 158). Tulevaisuuden merkitys on samalla noussut entistä tärkeämmäksi - kenen visio toteutuu? - ja menneisyys on menettänyt kiinnostavuuttaan tulevaisuuden rinnalla.

\section{Arjen temporaalisuus}

Viestinnän kolmas tärkeä yhteys aikaan on viestintävälineiden suuri vaikutus arjen temporaalisuuden muodostumisessa. Viestimet rytmittävät nyky-yhteiskunnan päivää aamusta yöhön, viikosta viikkoon ja vuodesta toiseen. Aamun ja iltapäivän lehdillä sekä radio- ja etenkin televisio-ohjelmilla on olennainen merkitys ihmisten päivittäisten rituaalien ajoittajina ja toiminnan koordinoijina (Scanneli 1995, 19-20, 39-42). Viestinten käyttö luo yhteisen rytmin, joka on välttämätön kaupungistuneen yhteiskunnan pysymiselle toimintakykyisenä: tietoisuus yhteisön muiden jäsenten samanaikaisesta toiminnasta luo turvallisuuden ja yhteisöllisyyden tunnetta. Viestintävälineiden samanaikainen käyttö ilmenee muun muassa katsojatutkimuksissa, puhelinten käyttöpiikeissä ja jopa katujen hiljenemisenä suosituimpien ohjelmien aikaan.

Viestimillä on merkittävä vaikutus yhteiskunnassa juuri toimintojen ajoituksen yhtenäistäjänä, mikä vahvistaa sosiaalista, yleistä aikaa ja tekee jossain muussa ajassa elämisen erittäin hankalaksi. Tämän vuoksi myös edellä käsitellyt aikakäsityksen ja -perspektiivin muutokset ovat merkittäviä: ne osoittavat kuinka viestintätavoilla on voimakas vaikutus ihmisten tapaan käsittää maailmaa ja kuinka viestintävälineillä on valta homogenisoida näitä käsityksiä. Olisi vaikea kuvitella sellaisen yhteiskunnan toimintaa yhteisönä, jossa ei olisi viestintävälineiden kaltaista "liimàa" yhtenäistämässä mielen kategorioita. Nyky-yhteiskunnassa voi olla vaikka kuinka monta kelloa, kirkkoa tai liikennevälinettä, mutta silti aikakäsitys ei yhtenäisty, ellei jokin yhdistä ihmisiä toisiinsa ja yhteisöönsä. Viestinnän “unohtaminen" aikakäsitykseen vaikuttavista tekijöistä on merkillistä tätä taustaa vasten katsottuna. 
Viestintävälineiden luoma temporaalisuus ei yhdistä vain yhden yhteisön jäseniä, vaan myös eri yhteisöt toisiinsa. Tästä ovat selkeänä esimerkkinä suuret kansainväliset urheilukilpailut, joiden televisiointi yhdistää maailman kolkat toisiinsa samanaikaisesti. Temporaalinen yhdenmukaistuminen toimii jo normaalienkin ohjelmien kautta: länsimaiset televisiosarjat ovat levittäneet omaa aikamaailmaansa jo vuosikausia muuhun maailmaan. Myös 24 tuntia vuorokaudessa toimivat kansainväliset satelliittikanavat korostavat enimmäkseen länsimaista, nopeaan tempoon keskittyvää rytmitystä. Vaikka viestintä ei poistakaan aikaeroja, se on tehokas toimija aikakäsityserojen poistajana.

\section{Elämänrytmin nopeutuminen}

Viestinnän ja ajan neijäs leikkauskohta on viestintävälineiden vaikutus ihmisten elämisen rytmin nopeutumiseen ja ajan muuttumiseen yhteiskunnan niukimmaksi resurssiksi. Vielä oraalisen ja käsinkirjoitetun viestinnän kausilla rytmit olivat hitaita ja viestintä vei paljon aikaa, etenkin eri seutujen välillä. Oraalisen kauden viestinnän ominaispiirre oli hidastempoisuus, mikä helpotti sekä puhujan että kuulijan muistin toimintaa (Riesman 1960, 110). Hitaus ja muistaminen saatiin aikaan ennen muuta sanojen ja lauserakenteiden toistoilla, mikä on esimerkiksi Ongin mukaan (1982, 40) ajattelulle luonnollinen tapa toimia, toisin kuin niukka lineaarisuus.

Muisti oli joustava ja kätevä väline, mutta liian hidas ja lyhytaikainen kirjoitusja painotaitoon verrattuna. Kirjoja kopioivien munkkien "taistelu aikaa vastaan" tekstien säilyttämiseksi turvassa ajan hampailta ei enää riittänyt, kun yliopistojen määrä alkoi renessanssin aikana kasvaa ja kysyntä kirjojen kopioista kasvoi. Vanhojen kirjojen tutkiminen ja vertaaminen vei paljon aikaa, kun kopioita oli vähän ja etäisyydet olivat suuria (Smith $1980,5,7$ ). Kopioimista oli yritetty nopeuttaa jo 1200-luvulla siirtymällä käsinkirjoituksessa varhhasta monastisesta tyylistä kursiiviin (Clanchy 1979, 260), mutta se ei riittänyt tyydyttämään kirjojen kysynnän kasvua.

Painotaidon keksiminen alkoi nopeuttaa rytmejä, kun ensin kirjoja alettiin tuottaa massatuotantona ja erityisesti silloin, kun lehdistö aloitti toimintansa (Eisenstein 1983, 6-7, 13). Lehtien kilpailukeinoksi tuli varsin pian uutisten nopea julkaiseminen, mikä kiihtyi varsinkin sähköisen viestinnän kauden alettua lennättimen johdolla. Uutistoiminnassa nopeudesta tuli yksi tärkeimmistä kriteereistä. Kilpailukeinona nopeuden tavoittelu levisi pian myös muille aloille: erityisesti puhelimen hankkiminen oli 1800-luvun lopun yrityksille merkittävä keino toiminnan nopeuttamiseksi (Aronson 1977, 26-31).

Lehdistö toi mukanaan myös toisen aikaan liittyvän muutoksen, "sapatin valloituksen", kuten James Carey $(1981,88)$ ilmiötä nimittää. Viestintä tunkeutui lehdistön myötä viime vuosisadan lopulla uuteen ajan dimensioon, alueelle, joka oli ennen pyhä: sunnuntaihin. Heprealaisten alunperin vaalima sapattiperinne eli tuolloin edelleen; oli olemassa aika, joka ei ollut valtion tai kaupan hallitsemaa vaan elämän muille puolille tarkoitettua. Sapattiperinne rikkoutui, kun lehtikeisari Hearst ensimmäisenä alkoi julkaista New York Sunday World -lehteä 1880-luvulla. Ajatus sunnuntailehdistä tai -lukemisesta oli siihen asti ollut Yhdysvalloissa tuntematon. Nyt syntyi uusi ilmiö - sapattimarkkinat - joka on laajentunut voimakkaasti etenkin tällä vuosisadalla.

Myöhemmin sähköiset viestimet täydensivät viestinnän tunkeutumista aikaan. Sunnuntain lisäksi viestimet valloittivat toisenkin ajan alueen: yön (Carey 1981, 88-89). Ihmisten aktiivisen päivän venyminen myöhempään iltaan alkoi jo lennättimen ja puhelimen mahdollistaessa yhteydenpidon toisiin aikavyöhykkeisiin ja yritysten laajentaessa toimintaansa ajassa. Yötyöläisten määrä alkoi lisääntyä ja 
samalla tarve viihteelle myös yöaikaan. Viestintävälineiden toiminnan laajeneminen on ollut sekä syy että seuraus suhteessa ihmisten toiminnan laajenemiseen yöhön. Kun radio- ja tv-yhtiöiden teettämissä ajankäyttötutkimuksissa huomattiin tarve myöhäisillan ja yölähetysten lisäämiseen, saivat uudet ohjelmat lisää ihmisiä valvomaan hieman myöhempään kuin aiemmin. (Melbin 1978a, 100, 105; 1978b, 4)

Tällä vuosisadalla yhteiskunnan rytmi on jatkanut nopeutumistaan, ensin radion ja television ja nyt tietokoneiden avulla jo yli ihmisen käsityskyvyn. Silmänräpäyksellisen nopean sähköisen viestinnän keksiminen, mikä teki simultaanisuudesta viestinnässä totta, vaikutti vuosisadan vaihteen ihmisten tapaan käsittää erityisesti nykyisyyttä, nopeutta ja etäisyyttä. Vaikutus oli voimakkain käsitykseen nykyhetkestä, joka laajeni käsittämään tapahtumat koko maailmassa. Lennätin, puhelin, päivittäiset sanomalehdet, standardiaika ja elokuva toivat simultaanisuuden teknologiaan, mikä tuli dramaattisesti esiin esimerkiksi Titanicin onnettomuudessa, jolloin SOS-viestit kuuluivat koko Atlanttia ympäröivälle alueelle. (Kern 1983, 1, 6, 314-315)

Viestinten katsottiin jopa tulleen täydellisiksi ja voittamattomiksi sähköisen nopeutensa vuoksi, koska ne poistivat kaikki ajan ja paikan viestinnälle tuomat rajoitteet. Kukaan ei enää olisi vieras toisille, kun yhteydenpito ympäri maailmaa hoitui hetkessä (Marvin 1988, 192-193, 199-201). Sähkön rajattomiin mahdollisuuksiin luottava ajattelu sai aikaan puheita myös laitteista, joita ei ollut edes olemassa. Yksi näistä oli "telectroskooppi", eräänlainen sähköinen kaukonäkölaite ja yksi television esi-isistä. Vanha kuvienkatselulaite, stereoskooppi, ei enää riittänyt, koska siitä puuttui simultaanisuuden vaikutelma, joka oli syntynyt ajatteluun sähkön myötä (Huhtamo 1992, 16). Viestinnän nopeutumisen vuoksi ihmiset halusivat yhtäkkiä tietää kaiken mitä kaikkialla tapahtui, koko länsimaailma heitettiin uuteen tapaan käsittää aikaa. Tapahtui ajan vallankumous, joka lyhensi ajan kestoa, kiihdytti jaksoittaisuuden lähelle simultaanisuutta, ja sai aikaan tapahtumien ajoittamisen tunteihin, minuutteihin ja jopa sekunteihin (Rifkin 1987, 145147). Samalla koko yhteiskunnan elämisen tahti kiihtyi.

Lennättimen tuomasta "uutistulvasta" huolestuneet vuosisadan vaihteen ajan neurologit pystyivät tuskin edes aavistamaan, kuinka reaaliaikaiseksi ja salamannopeaksi viestien välityksen oli mahdollista muuttua. Huoli nopeutuvien rytmien vaikutuksesta ihmisten psyykeen ei sen sijaan ole muuttunut lainkaan: nykypäivän psykologit tutkivat tietokoneiden ajan seurauksia "ongelmakäyttäjillä" (Rifkin 1987, 15-17). Tulosten, jotka kertovat hermostuneisuudesta, lyhytjänteisyydestä ja hitauden sietämättömyydestä, on syytäkin herättää kysymyksiä siitä, onko teknologiamme nopeus jo ajanut sopeutumiskykymme ohi.

\section{Ajan merkityksen kasvu}

Kaikki edellä käsitellyt viestinnän ja ajan yhteydet liittyvät niiden viidenteen yhteyteen: siihen, miten viestinnän muutokset ovat vaikuttaneet ajan muuttumiseen ennennäkemättömän tärkeäksi käsitteeksi. Muutos oraalisista yhteiskunnista, joissa aikaa ei esiintynyt edes kielen sanana nykypäivään on valtava. Ajalla alkoi olla sähkön kaudella yhä tärkeämpi merkitys kuljetuksessa, viestinnässä ja sodankäynnissä, joissa kaikissa tarvitaan tarkkaa tietoa ihmisten, tiedon ja materiaalien lähtö- ja saapumisajoista. Jotta kaikki osapuolet voisivat olla tyytyväisiä, heillä täytyy olla yhtenäinen käsitys ajasta. Paineet standardiajan luomiseen alkoivat olla suuria sekä maiden sisäisessä että maiden välisessä liikenteessä (Landes 1983, 93-94). Juuri kansallisten ja kansainvälisten viestintäverkkojen muodostuminen rautatien ja lennättimen jälkeen sai lopulta aikaan standardiajan asettamisen (Zerubavel 1982, 1, 5-6). 
Lehdistön synnyn myötä syntyi myös yksi ensimmäisistä ikuisesti aikaa vastaan taistelevista ammattikunnista: toimittajakunta. Etenkin päivittäisissä viestimissä toimittajien työ on tiukasti ajan hallitsemaa: esimerkiksi uutislähetysten kokoaminen on minuuttien laskemista, deadlineen kiirehtimistä ja kilpailua uutisten julkaisunopeudesta muiden viestinten kanssa (Schlesinger 1987, 83-105). Viestinten niukasta ajasta kilpailevat etenkin poliitikot, joille näkyminen tarpeeksi usein viestimissä on uran elinehto. Varsinkin suurissa länsimaissa poliitikkojen esiintymiset viestimissä on ajoitettu sekunnilleen, jotta saavutettaisiin haluttu vaikutus. Tämä pitää paikkansa erityisesti vaalimainonnassa. Mainonta on yksi viestinnän ala, joka on erittäin "aikatietoinen". Mainostajien on sanottava asiansa muutamissa kymmenissä sekunneissa, mikä tekee ajan äärimmäisen tarkan laskemisen välttämättömäksi.

Ihminen on alkanut kehittää aikaa "säästäviä" keinoja ja laitteita sen jälkeen, kun ajasta tuli niukka resurssi ja sen puute alkoi olla ongelma. Yksi näistä laitteista on tietokone, jonka piti tehdä osansa ihmisen ajan vapauttamisessa. Näyttää kuitenkin siltä, että uusi teknologia on tehnyt meistä entistä aikatietoisempia ja sitä kautta myös stressaantuneempia. Jos tietokone on vapauttanut aikaa, se on vapauttanut sen useimmiten muiden töiden tekoon. Ajan hampaista ihminen ei kuitenkaan ole päässyt minnekään. Ajan niukkuus yhteiskunnassa on johtanut myös ihmisten tapaan säästää aikaa ostamalla palveluja, esimerkiksi tietoa (Bell 1973, 473). Tämä on osaltaan vahvistanut viestintävälineiden merkitystä yhteiskunnan tiedonvälittäjinä, jotka keräävät ihmisille päätöksentekoa varten tarvitut välttämättömät tiedot. Samalla viestintävälineiden merkitys ajattelutapojen muokkaajana voimistuu entisestään, jos ajan niukkuus samanaikaisesti karsii ihmisen henkilökohtaisia kontakteja yhteisönsä muihin jäseniin.

Edellä olevassa tarkastelussa olen pyrkinyt osoittamaan viestinnän keskeisen merkityksen aikakäsityksen muutoksissa sekä viestinnän ja ajan selkeän liittymisen yhteen. Tutkimus tästä aiheesta on erityisen vähäistä, minkä vuoksi tutkimuksille viestinnän ja ajan yhteyksistä on runsaasti aiheita sekä keskinäis-, organisaatio- että joukkoviestinnän ja viestinnän yleisen teorian alueella. Esimerkiksi yksittäisten medioiden suhdetta aikaan on tutkittu erittäin vähän: niin elokuvan, radion kuin televisionkin tavat käyttää ja manipuloida aikaa olisivat mielenkiintoisia tutkimuskohteita katsottuna ihmisten aikakäsityksen muodostumisen kannalta. Selvitys ajan manipulaatiosta medioissa olisi erityisen tärkeää uutisten aikamaailman ymmärtämiseksi ja jotta selkeästi tulisi esille se, että uutisten ajallisen esittämisen järjestys ei vastaa niiden todellista kronologista järjestystä. Tutkimusta kaivattaisiin myös siitä, kuinka mainostajat ja poliitikot käyttävät viestinten aikaa työssään, jotta tavat vaikuttaa mielipiteisiin saisivat lisävaloa. Viestinten aika on etenkin poliitikoille tärkeä vallankäytön keino, jota on tutkittu melko vähän aiheen tärkeydestä huolimatta.

Myös viestinten tunkeutuminen aikaan, josta tässä artikkelissa oli esimerkkinä sunnuntain ja yön valloitus, on melko tutkimaton alue. Viestintä on jatkanut leviämistään edelleen niin ajassa kuin paikassakin, esimerkiksi Suomessa inmisten kesämökeille ja tietokoneverkkojen kautta koteihin eri puolilla maailmaa. Tämän leviämisen vaikutus viestinten asemaan ajattelun muokkaajana olisi tärkeä tutkimuksen kohde. Ajan ja tilan tutkiminen yhdessä suhteessa viestintään laajentaisi tutkimusten kattavuutta. Tilasta on olemassa jonkin verran sosiologista tutkimusta, mutta sen yhteys viestintään on jäänyt melko vähälle huomiolle. Aihetta voisi lähestyä esimerkiksi tutkimalla viestinnän leviämistä tilassa uusille alueille ja sen vaikutusta ajan käsittämiseen sekä kulttuurisen tempon muuttumiseen näillä alueilla. Erilaisten aikakäsitysten vaikutukset viestintätapoihin on myös alue, joka kaipaa lisätutkimusta.

Tärkeää olisi myös tutkimus uusien medioiden vaikutuksesta aikakäsitykseemme, jotta syntyisi keskustelua siitä, tuoko viestinnän jatkuva nopeutuminen myös 
ei-toivottuja seurauksia ihmisten psyykeen. Jos rytmien tahdin kiihtyminen jatkuu, kuinka ihmisiä voidaan auttaa jäsentämään maailmaa uutistulvan keskellä? Onko tietokoneaddiktien väitetty lyhytjänteisyys todella tulosta koneiden vaikutuksesta ja jos näin on, niin kuinka asiaan voidaan vaikuttaa? Nopeutuvien viestintätekniikoiden tulevaisuuden kartoitus olisi ensiarvoisen tärkeää. Arjen temporaalisuuden kiivas tahti on pitkälti viestinten ylläpitämää ja siksi viestinnän tutkimuksen tulisi osallistua myös sen seurauksien pohtimiseen.

\section{Kirjallisuus}

Aronson, Sidney $\mathrm{H} .(1977)$

Bell's Electrical Toy: What's the Use? The Sociology of Early Telephone Usage

Teoksessa Pool, Ithiel de Sola (ed.) The Social Impact of the Telephone. Cambridge: The MIT Press, 15 - 39

Bell, Daniel (1973)

The Coming of Post-industrial Society. A Venture in Social Forecasting. New York: Basic Books.

Bolter, J. David (1984)

Turing's Man: Western Culture in the Computer Age. Chapel Hill: The University of North Carolina Press.

Bourdieu, Pierre (1990)

Time Perspectives of the Kabyle. Teoksessa Hassard, John (ed.) The Sociology of Time. London: Macmillan

Press, $219-237$

Broms, Henri (1984)

Alkukuvien jäljillä. Kulttıurin semiotiikkaa. Juva: WSOY

Carey, James W. (1981)

Culture, Geography, and Communications: The Work of Harold Innis in an American Context. Teoksessa

Melody, William H., Salter, Liora R. \& Heyer, Paul (eds.) Culture, Communication and Dependency

The Tradition of H.A. Innis. New Jersey: Ablex Publishing Corporation.

Carpenter, Edmund (1960)

The New Languages. Teoksessa Carpenter, Edmund \& McLuhan, Marshall (eds.) Explorations in

Communication. An Anthology. Boston: Beacon Press, 162 - 179.

Clanchy, M. T. (1979)

From Memory to Written Record. England 1066 - 1307. London: Edward Arnoid.

Durkheim, Emile (1980)

UskontDelämän alkeismuodot. Australialainen toteemijärjestelmä. Helsinki: Tammi.

Eisenstein, Elisabeth L. (1983)

The Printing Revolution in Early Modern Europe. Cambridge: Cambridge University Press

Evans-Fritchard, E. E. (1974)

The Nuer. A. Description of the Modes of Livelihood and Political Institutions of a Nilotic People. New York Oxford University Press.

Ferguson, Marjorie (1990)

Electronic Media and the Redefining of Time and Space. Teoksessa Ferguson Marjorie (ed.) Public

Communication. The New Imperatives. Future Directions for Media Research. London: Sage Publications.

Giddens, Anthony (1984)

Yhteiskuntateorian keskeisiä ongeimia. Toiminnan, rakenteen ja ristiriidan käsitteet yhteiskunta-amälyysissä Heisinki: Otava

Goody, Jack (1968)

Time: Social Organization. Teoksessa Sills, David L. (ed.) International Encyclopedia of the Social Sciences

vol. 16. New York: Macmillan \& The Free Press, $30-42$.

Goody, Jack (1977)

The Domestication of the Savage Mind. Cambridge: Cambridge University Press.

Goody, jack \& Watt, lan (1962)

The Consequences of Literacy. Comparative Studies in Society and History 5: $304-345$

Hallowell, A. Irving (1937)

Temporal Orientation in Western Civilization and in a Preliterate Society. American Anthropologist,

New Series, Vol. 39:647 - 670

Huhtamo, Erkki (1992)

Ennen broadcastingia. Lähikuva, ri:o 1/1992:6 - 17

Innis, Haroid Adams (1950)

Empire and Communications. London: Oxford University Press

Innis, Harold Adams (1951)

The Bias of Communication. Toronto: University of Toronto Press.

Innis, Harold Adarns (1952)

Changing Concepts of Time. Toronto: University of Toronto Press.

Julkunen, Raija (1989)

Jokapäiväinen aikamme. Teoksessa Heiskanen, Pirkko (toim.) Aika ja sen ankaruus

Helsinki: Gaudeamus, $10-21$.

Kern, Stephen (1983)

The Culture of Time and Space 1880 - 1918. Cambridge, MA: Harvard University Press. 
Landes, David S. (1983)

Revolution in Time. Clocks and the Making of the Modern World. Cambridge: The Belknap Press of Harvard University Press

McLuhan, Marshall (1984) Ihmisen uudet ulottuvuudet Porvoo: WSOY

Marvin, Carolyn (1988) When Old Technologies Were New. Thinking About Communications in the Late Nineteenth Century. New York: Oxford University Press

Melbin, Murray (1978a) The Colonization of Time. Teoksessa Caristein, Tommy, Parkes, Don \& Thrift, Nigel (eds.) Timing Space and Spacing Time. Volume 2. Human Activity and Time Geography. London: Edward Arnold.

Melbin. Murray (1978b) Night as Frontier. American Sociological Review, Vol. 43, No. 1: $3-22$.

Mumford, Lewis (1963) Technics and Civilization. San Diego: Harcourt Brace Jovanovich

Ong. Walter J. (1982) Orality and Literacy. The Technologizing of the Word. London: Routledge.

Pohjanen, Jorma (1992) Kello on 8.00 , mutta mitä on aika. Pyrkimiyksiä ajan sosiaaliseen käsittämiseen. Oulun yliopistor sosiologian laitoksen tutkimuksia n:o 19

Riesman, David (1960) The Oral and Written Traditions. Teoksessa Carpenter, Edmund \& McLuhan, Marshall (eds.) Explorations in Communication. An Anthology. Boston: Beacon Press, $109-115$.

Rifikin, Jeremy (1987) Time Wars. The Primary Conflict in Human History. New York: Henry Holt and Company. Scannell, Paddy (1995) History, Media, Communication. Julkaisematon käsikirjoitus. Schlesinger, Philip (1987) Putting "Reality" Together. BBC News. London: Methuen.

Schudson, Michael (1991) Historical Approaches to Communication Studies. Teoksessa Jensen Klaus Bruhn \& Jarikowski Nicholas W. (eds.) A Handbook of Qualitative Methodologies for Mass Communication Research. London: Routledge. Smith, Anthony (1980) Goodbye Gutenberg. The Newspaper Revolution of the 1980's. New York: Oxford University Press. Sorokin, Pitirim \& Merton, Robert (1990) Social-time: A Methodological and Functional Analysis. Teoksessa Hassard, John (ed.) The Sociology of Time London: Macmilian Press, $56-66$.

Tuchman, Gaye (1980) Making News. A Study in the Construction of Reality. New York: Free Press

Zerubavel, Eviatar (198i) Hidden Rhythms. Schedules and Calendars in Social Life. Berkeley: University of California Press.

Zerubavel, Eviatar (1982) The Standardization of Time: A Sociohistorical Perspective. American Journal of Sociology 88, 1: 1-23. 


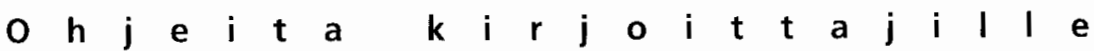

Käsikirjoitukset toimitetaan kar tena kappaleena päätoimittajalle tai toimitussihteerille. Käsikirjoituksen ensimmäiselle sivulle or merkittävä nimen ja osoitteen lisäksi oppiarvo, virka-asema ja toimipaikka. Levykkeillä toimitettuihin juttuihin on liitettävä myös paperikopiot käsikirjoituksesta.

Artikkeliosastossa julkaistaan empuirisiä, teoreettisia ja metodologisia kirjoituksia tai erittelyjä käynnissä olevasta tutkimustoiminnasta tai kiinnostavasta kirjaliisuudesta. Kirjoittajan tavoitteena olkoon sujuvakielnen, naseva ja persoonallisella tyylillä esitetty tieteellinen proosa.

Petiittiosastossa juikaistaan häastatteluja ja muita ajankohtaisia kirjoituksia sekä vaihtelevaa materiaalia keskustelupuheenvuoroista kirjâ-arvosteluinin ja alaa koskeviir uutisiin.

Toimitus ja sen nimeämä asiantuntija arvioivat käsikirjcituksen. Kifjoitukseen voidaan esittää muutoksia, jotka kirjoittajan edellytetään tekevän. Artikkelin tekstin maksimipituus on 20 liuskaa.

Käsikirjoituksen ulkoasusta on huomattava: Käsikirjoitusliuskan tulisi sisältüäa korkeintaarı 28 riviä. Kuviot ja taulukot on laadittava erilliselle paperille. Kuvioiden on oltava puntaaksi pirretyssä muodossa.

Artikkeieista ja tutkimusselosteista sekä laajemmista katsauksista on kirjoitettava erillinen, korkeintaan 10 rivin pituinen tiivistelmä, jossa esitetään tutkimuksen tarkoitus ja kohde sekä johtopäätökset.

Lähdeviitteet sijoitetaan kirjoituksen sisään sulkeislin siten, että ensimmäiseksi tulee kirjoittajan sukunimi, sıtten kirjoituksen painovuosi ja viittauksen sivunumerot, esim. (Hemánus \& Tervonen 1980, 110-115).

Lähdeluettelo liitetään kirjoituksen loppuun otsikolla kirjallisuus. Luettelo laaditaan tekiiän sukunimen mukaisessa aakkosjärjestyksessä, seuraavaa käytäntoä seuraten.

Teokset: tekijä, ilmestymisvuosi, teoksen nimi, (julkaisusarja ja numero), painopaikka ja kustantaja. Esimerkiksi: Bourdieu, Pierre (1984)

Distinction. A Social Critique of the Judgement of Taste. Cambdridge: Harvard University Press.

tai

Pietilä, Kauko (1980)

Formation of the Newspaper: A Theory. Acta Universitatis Tamperensis, Ser. A, Vol. 119. Tampere: Tampereen yliopisto

Artikkelit lehdissä: tekijä, ilmestymisvuosi, artikkelin otsikko, lehder, nimi, vuosikerta, ilmestymisvuosi ja lehden numero sekä artikkelin sivunumerot. Esimerkiksi;

Pietilä, Veikko (199i)

Sanoista tekoihin. 'Vieraan puheen' vastaanotosta sanomalehtiuutisessa. Tiedotustutkimus 14(1991):4, 5-18.

Artikkelit kokoomateoksissa: Tekijä, ilmestymisvuosi, artikkelin otsikko, teoksen toimittajat, teoksen rimi, painopaikka ja kustantaja sekä artikkelin sivunumerot. Esimerkiksi:

Adorno, Theodor (1960)

Television and the Patterns of Mass Culture. Teoksessa Schramm, Wilbur (ed.) Mass Communications. Urbana: University of llinors Press, 594-612.

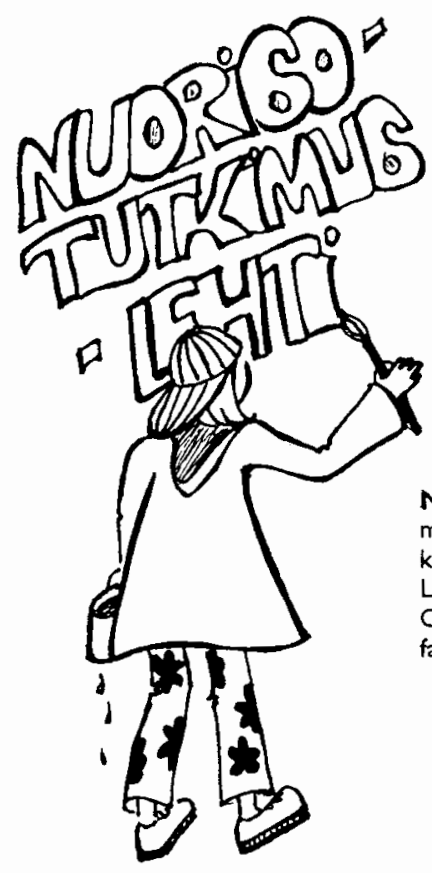

NUORISOTUTKIMUS-lehti esittelee, kuvaa ja tulkitsee nuorten elämän koko kirjoa. Vuoden 1996 teema-alueina ovat: Nuoruuden julkisuus (1/96), Musiikki (2/96), Vastarinta (3/96), Kuolema (4/96). Lehden vuosikera on $100 \mathrm{mk}$. Tilaukset: Nuorisotutkimusseura, Olympiastadion, Eteläkaarre, 00250 Helsinki p. $90-34824323$. fax.90 - 49| 290, sähköposti: leenas@allifi. HYPPÄÄ MUKAAN! 